\title{
Development and Evaluation of an Isolated Resonant Converter for Auxiliary Power Supply in DC Traction
}

\author{
Veera Venkata Subrahmanya Kumar Bhajana \\ School of Electronics Engineering \\ Kalinga Institute of Industrial Technology \\ Bhubaneswar, India \\ bvvs.kumarfet@kiit.ac.in
}

\author{
Pavel Drabek \\ Regional Innovation Centre for Electrical Engineering \\ University of West Bohemia \\ Pilsen, Czech Republic \\ drabek@ieee.org
}

\begin{abstract}
This paper presents the implementation and evaluation of an isolated resonant converter and also compares the efficiencies of hard and soft switching isolated converter topologies using high-frequency transformer for auxiliary power supplies in DC traction. The half-bridge DC-DC converter with resonant network has been tested under zero voltage switching (ZVS), zero current switching (ZCS) operations, and also dead time variation of the power switches improving the overall system efficiency. This paper provides guidelines for a cost effective DCDC converter design based on discrete 1200V/40A IGBTs driven with high switching frequency. That would allow optimization of passive elements by reducing their mass making the converter suitable for traction application. Simulations and test results of an experimental setup with output power up to $3 \mathrm{~kW}$ are presented. The overall system efficiency of the ZVS and ZCS operations of half-bridge LLC DC-DC converter were compared with a classic hard switching topology.
\end{abstract}

Keywords-ZVS; ZCS; half bridge resonant converter; LLC; DC-DC; auxiliary power supply

\section{INTRODUCTION}

Typical light traction vehicles contain electrical equipment such as air brakes, cooling system, air pressures, fans etc. supplied from a standard $3 \times 400 \mathrm{~V}_{\mathrm{AC}}$ on-board power grid. The grid is generated by a structure of dedicated converters which usually provide battery charging functionality. The design of such an auxiliary power supply has to respect the fact that the catenary voltage of nominal voltage $600 \mathrm{~V}_{\mathrm{DC}}$ or $750 \mathrm{~V}_{\mathrm{DC}}$ may vary in the range of $400 \mathrm{~V}_{\mathrm{DC}}$ to $950 \mathrm{~V}_{\mathrm{DC}}$. Also, the outputs, i.e. the power grid or the battery charger, must be isolated in order to maintain a high level of safety. The overall structure of an auxiliary power supply (without a battery charger branch) used in practice consists of the input voltage stabilizer (IVS), supplied from the catenary through, which stabilizes voltage to the catenary lower range level, and the half-bridge (HB) isolating converter. Due to additional requirements from vehicle manufacturers concerning small size and low weight, high frequency operations with reduced losses allowing further savings in passive components mass and volume become key parameters of the converter in the auxiliary power supply.

The resonant network topology suggested in [1] provided useful soft switching operations for the isolated dual bridge
DC-DC converters. To obtain ultra-high input and better efficiency in a DC-DC converter [2], different combinations of type-4 series resonant networks were reported. A burst oscillation control [3] has been used to improve the efficiency of current resonant, full bridge and half bridge converters. These converters achieved the highest efficiency at low and high output power levels. For the applications of on-board charging, an LLC resonant converter [4] operated under continuous conduction mode achieved ZVS turn-on operation to their MOSFETs. A half bridge LLC resonant converter is described in [5] for low power applications with higher switching frequency and digital control system developed for multi resonant network [6] for DC-DC converters. A half bridge converter has been developed with a simple resonant inductor, capacitor and an additional switch, and obtained ZVS operation with $94.5 \%$ efficiency at $350 \mathrm{~W}$ output power in [7]. A ZVS full bridge resonant converter has been implemented in [8] by utilizing simple resonant elements and obtained $93.3 \%$ efficiency at $8 \mathrm{~kW}$ output power. A low power full bridge converter [9] attained ZVS operation by the additional resonant network. However, it had poor efficiency at low output power. A half bridge resonant converter with voltage rectifier attained soft-switching (ZVS) operation to their MOSFETs and achieved $96 \%$ efficiency below $100 \mathrm{~W}$, was studied in [10].

This paper focuses on the high power DC/DC isolating converter which converts stabilized voltage $380 \mathrm{~V}_{\mathrm{DC}}-390 \mathrm{~V}_{\mathrm{DC}}$ (has to be lower or higher than input catenary voltage range) to a level suitable for the consequent appliances (standardly $560 \mathrm{~V}_{\mathrm{DC}}$ to supply VSI to produce output power grid $3 \times 400 \mathrm{~V}_{\mathrm{AC}}$ ). Half bridge topology was chosen for the study as it offers lower prices. In order to achieve maximum efficiency, a resonant network was utilized, allowing higher switching frequency at reasonable efficiency level. In this paper, a half bridge resonant converter was verified under two different operating modes, continuous conduction and discontinuous conduction. Comparison was made between the effectiveness of this converter and the one of a conventional hard-switching converter. This article presents the operation principles, DC characteristics, simulation analysis, and laboratory tests conducted with the half bridge LLC resonant DC-DC converter. 


\section{OPERATION PRINCIPLES}

Figure 1 shows the schematic of a typical half bridge resonant DC-DC converter. The primary side contains four active IGBTs $S_{1}-S_{2}$, the resonant elements $C s, L s$, and the magnetizing inductance $\left(L_{m}\right)$. The turns ratio of the transformer is 1:1.5. The secondary side of the transformer includes rectifying diodes $D_{1}-D_{4}$, the filter capacitor $\left(C_{o}\right)$ and the load resistance $\left(R_{L}\right)$. The primary-side active switches are controlled with $50 \%$ duty cycle. When $S_{I}$ and $S_{2}$ conduct simultaneously, the input power is transferred to the output load. The zero voltage switching (ZVS) turn-on and zero current switching turn-off are achieved by the resonance of $L_{s}$ and $C_{s}$. Figure 2 shows the waveforms of half bridge LLC resonant DC-DC converter. The first stage is resonant current in continuous conduction mode, the operating frequency is above the resonant frequency and the second stage is resonant current in discontinuous conduction mode, with the operating frequency below the resonant frequency. In these stages, during continuous conduction mode, all the power switches can turnon under ZVS condition and in discontinuous conduction mode all the power semi-conductor switches can turn on/off under ZCS. Figure 2(a) shows the continuous conduction mode, resonant tank current $\left(i_{L r}\right)$, magnetizing inductance current $\left(i_{L m}\right)$, and switch current $\left(i_{S I}\right)$ waveforms and similarly Figure 2(b) shows the waveforms of the discontinuous conduction mode.

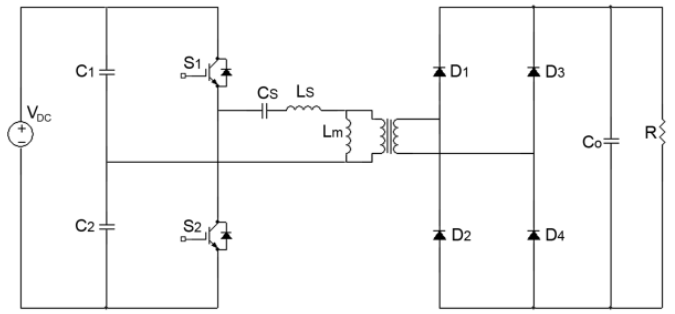

Fig. 1. Isolated half bridge LLC resonant converter

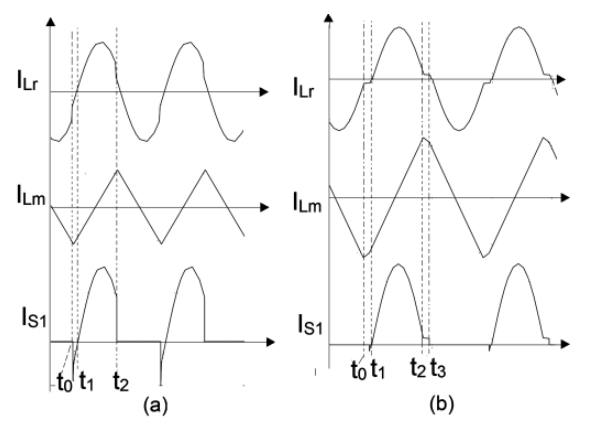

Fig. 2. Key waveforms: (a) CCM mode, (b) DCM mode

\section{A. Continuous Conduction Mode}

When the resonant frequency of the half bridge DC-DC converter is set below the switching frequency zero voltage, turning on of the converter power switches is possible. These conditions ensure that the resonant current $i_{L r}$ freewheels through the body diodes of the main switches prior to turn on, thus preventing turn on losses. Figure 2(a) shows the key waveforms for continuous conduction mode (CCM) of resonant half bridge converter. At $t=t_{0}$ the IGBT $S_{2}$ is turned off which forces the resonant tank current $i_{L r}$ to freewheel through the body diode of $S_{l}$, resonant tank. The voltages on $S_{l}$ basically the diode drop, become close to zero when the gate turn on pulse for $S_{1}$ applied at $t=t_{1}$. During the time from $t_{1}$ to $t_{2}, S_{1}$ is turned on, the output rectifier diodes $D_{l}, D_{4}$ conduct and energy is transferred to the secondary through the transformer. After the time $t_{2}$, the power switch $\left(S_{1}\right)$ is turned off, the body diode of $S_{2}$ creates the path for freewheeling the primary resonant tank current $i_{L r}$ which makes ZVS condition for the following $S_{2}$ turn on.

\section{B. Discontinuous Conduction Mode}

Figure 2(b) shows the discontinuous conduction mode (DCM) waveforms, At $t=t_{0}$ IGBT $S_{2}$ is turned off, the $L_{m}$ inductor current reaches maximum, and the resonant current drops to zero. The output rectifier diodes are also turned off. $S_{l}$ is turned on under ZCS at $t=t_{l}$. The resonance of the inductors $L_{s}$ and $C_{s}$ creates $\mathrm{i}_{\mathrm{Lr}}$ current in a sinusoid shape and the magnetizing inductor current decreases linearly. The switch $S_{l}$ is turned off under conditions close to ZCS at $t=t_{2}$. The $i_{L r}$ value at this moment equals to the magnetizing current of the transformer. After that the output capacitances of $S_{1}$ and $S_{2}$ are recharged by $i_{L r}$ until $S_{2}$ voltage reaches $V_{d c}$ when $S_{2}$ body diode is forced to conduct. It provides ZVS conditions for the subsequent $S_{2}$ turn on at $t=t_{3}$.

\section{DC CHARACTERISTICS AND DESIGN PROCEDURE}

\section{A. DC Characteristics}

The DC characteristics of the half bridge converter are obtained by experimental studies performed for steady state response. Voltage gain characteristics curves are illustrated in Figure 3, which shows that the resonance frequency is above the switching frequency. From the DC characteristics, it can be seen from peak gain changing by adjusting load. The peak gain measured values were taken at high load conditions.

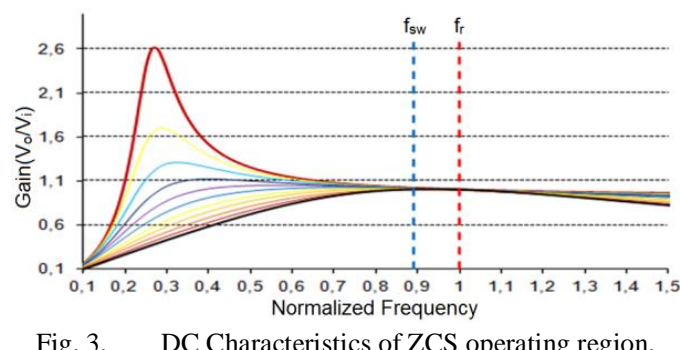

\section{B. Design Procedure}

Based on the theoretical analysis, the design procedure is presented in this section. It discusses that the resonant network can be suitable for traction applications. The equivalent circuit of the LLC resonant tank is shown in Figure 4. The load resistance $\left(R_{E}\right)$ shown in the primary side is defined as:

$$
R_{E}=\frac{8 n^{2}}{\pi^{2}} R_{o}
$$

Using the ac equivalent circuit of Figure 4, the voltage gain is expressed with the following parameters and definitions: 
Resonant frequency: $f_{r}=\frac{1}{2 \pi \sqrt{L_{s} C_{s}}}$

Characteristics impedance:

$$
Z=\sqrt{\frac{L_{s}}{C_{s}}}=2 \pi f_{r} L_{s}=\frac{1}{2 \pi f_{r} C_{s}}
$$

Quality factor: $Q=\frac{Z_{o}}{R_{E}}=\frac{Z_{o}}{n^{2} R_{o}}=\frac{\pi^{2} Z_{o} P_{o}}{8 n^{2} V_{o}^{2}}$

Inductance ratio: $\lambda=\frac{L_{s}}{L_{m}}$

Normalized frequency: $f_{n}=\frac{f_{s w}}{f_{r}}$

Voltage gain characteristics curves are shown in Figure 5. They curves show the resonance frequency is $90 \mathrm{kHz}$ when the switching frequency is $100 \mathrm{kHz}$, and the converter operates in ZVS region.

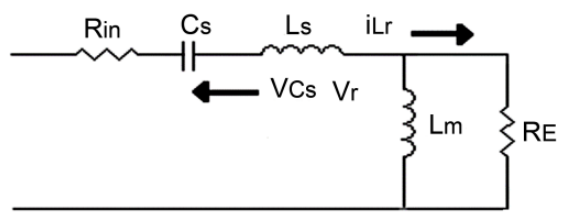

Fig. 4. Equivalent circuit of LLC

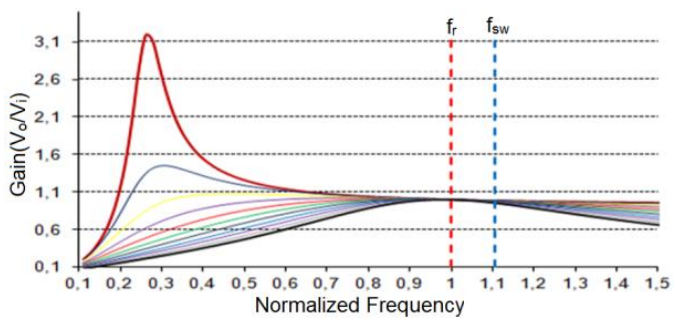

Fig. 5. DC Characteristics of ZVS operating region

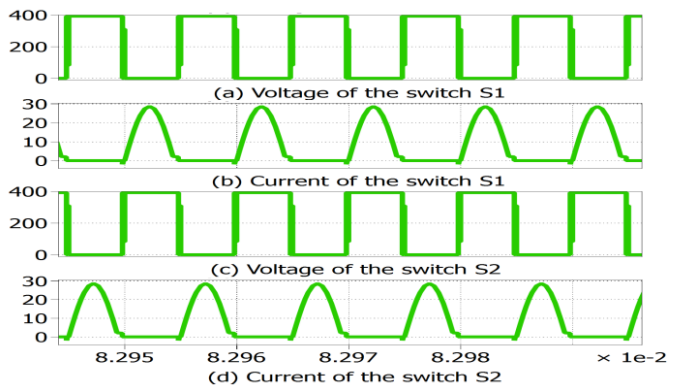

Fig. 6. Simulated results: Voltage and current through switches $S_{1}, S_{2}$ when the converter operates in ZCS region.

\section{SimUlation RESUlTS}

Simulation results were obtained separately for ZVS and ZCS by Matlab/Simulink. The simulation parameters used are mentioned in Table I. Figure 6 depicts switches' $\left(S_{1}\right.$ and $\left.S_{2}\right)$ voltage and currents, which show the ZVS operating region of the converter. Figure 8 illustrates switches' voltage and currents, which represent the ZCS operation of the converter. Figure 9 shows the voltage and current through the transformer in ZVS and ZCS regions.

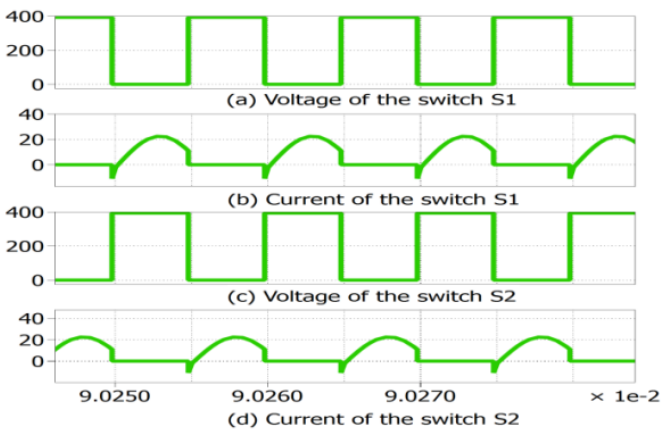

Fig. 7. Simulated results: Voltage and current through switches $S_{1}, S_{2}$ when the converter operates in ZVS region.
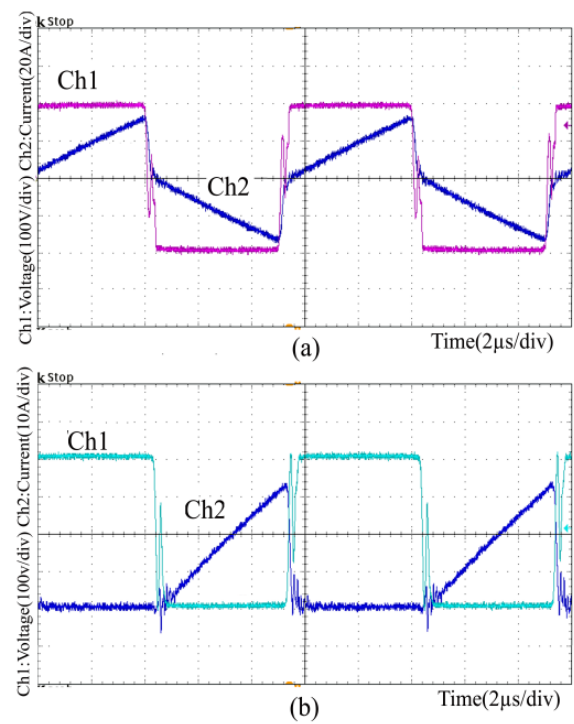

Fig. 8. (a) Measured waveforms of the primary side of the transformer: Voltage (Ch1), current (Ch2). (b) Measured waveforms of IGBT $S_{l}$ : Voltage (Ch1) current, (Ch2). Hard switching.

\section{EXPERIMENTAL RESULTS}

Laboratory tests were conducted for the two case studies under steady state operation. ZVS and ZCS conditions were tested separately in order to show the efficiency of the ZVS and ZCS converters separately. The design specifications (Table I) for this converter are $V_{\text {in }}=400 \mathrm{~V}, V_{\text {out }}=300 \mathrm{~V}, \mathrm{P}_{\text {out }}=1 \mathrm{~kW}$ to $3 \mathrm{~kW}$, switching frequency $100 \mathrm{kHz}$ and the switching device we used was IGBT IKW40N120H3. The resonant inductor $L_{s}=15 \mu \mathrm{H}$, the transformer magnetizing inductance $L_{m}=17 \mu \mathrm{H}$, and the resonant capacitor $C_{s}=130 \mathrm{nF} / 200 \mathrm{nF}$. The realization of DC-DC converter system is a low cost system to drive auxiliary systems in traction. Figure 9(a) shows the transformer primary side voltage and current waveforms of hard-switched half bridge converter and Figure 9(b) shows the device voltage and currents. Figure 10 depicts IGBT $\left(S_{l}\right)$ voltage and current 
waveforms for the ZVS operating region. Figure 11 shows the experimental waveforms of the transformer primary side voltage $\left(V_{P}\right)$ and resonant tank current $\left(i_{L r}\right)$.
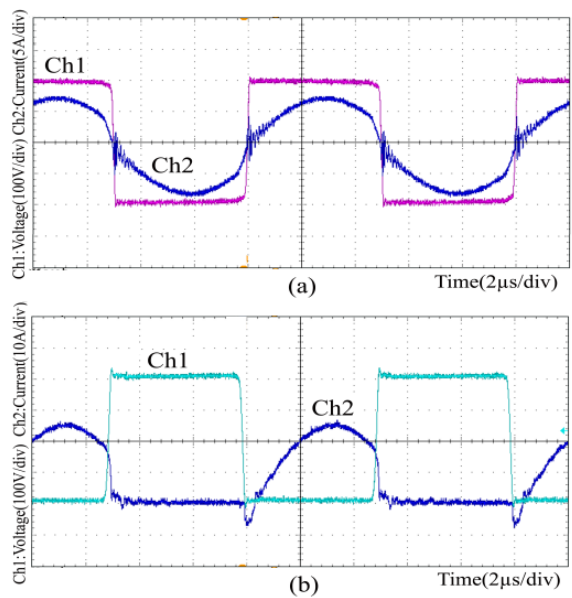

Fig. 9. Measured waveforms of the primary side of the transformer: Voltage (Ch1), current (Ch2). (b) Measured waveforms of IGBT $S_{l}$ : Voltage (Ch1), current(Ch2). CCM mode.
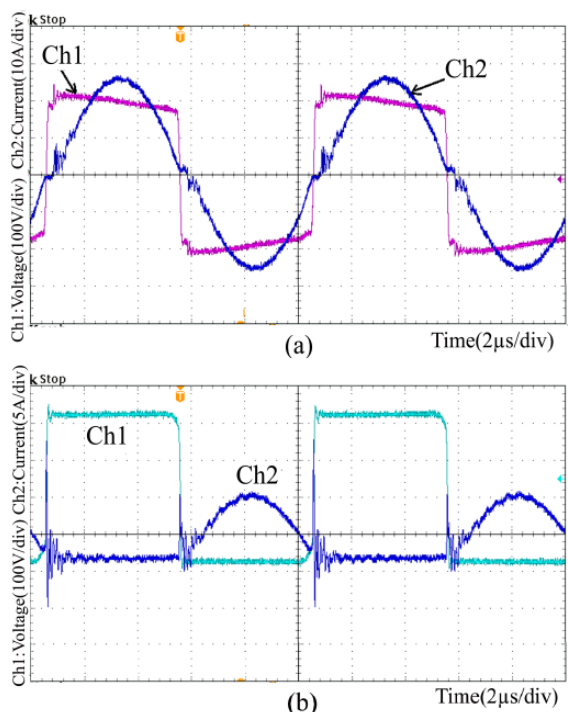

(b)

Fig. 10. (a) Measured waveforms of the primary side of the transformer: Voltage (Ch1), current (Ch2). (b) Measured waveforms of IGBT $S_{1}$ : Voltage (Ch1), current (Ch2). DCM mode.

\section{A. Observations Made by Varying Dead Time}

By varying the dead time between each switch, laboratory tests were conducted in order to observe the optimum efficiency of the converter. During the resonant cycle, all the power switches will transfer the output power. Two switches for a half of the resonant cycle and the other two for the next resonant cycle, maintaining the ZCS, but a delay is introduced between each switch turning on. Therefore the switch current transfers to the corresponding freewheel diode before returning to zero. The switch currents remain zero until the next switch turns on. Results shown in Figure 11 are obtained for dead time of $0.5 \mu \mathrm{s}$. By changing the dead time between switches to $0.9 \mu \mathrm{s}$, it is observed that all power switches are turned on under
ZVZCS. Also, the efficiency of the converter has been increased from $0.5 \%$ to $1 \%$, when comparing with ZCS operating region with $0.5 \mu \mathrm{s}$. Figure 12 (a)-(b) depicts the ZCS turn on with $0.5 \mu$ s dead time interval, which is having large current spikes when switches are turn on/off. Due to the large amount of spikes the efficiency is very poor. It is observed in Figure 12(c)-(d), that with $0.9 \mu$ s dead time, ZVZCS turn on is achieved and the overall system efficiency is improved. Figure 13 shows the collector-emitter voltage and current of the switch $\left(S_{I}\right)$, when it is operated in ZVS and ZCS regions.
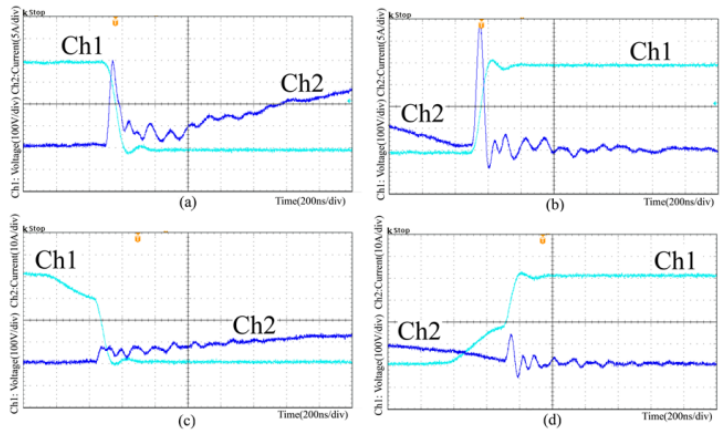

Fig. 11. (a) Measured waveforms of IGBT $S_{l}$ voltage and current of the switch with $0.5 \mu$ s dead time. (b) Measured waveforms of IGBT $S_{I}$ voltage and current of switch with $0.9 \mu$ s dead time.
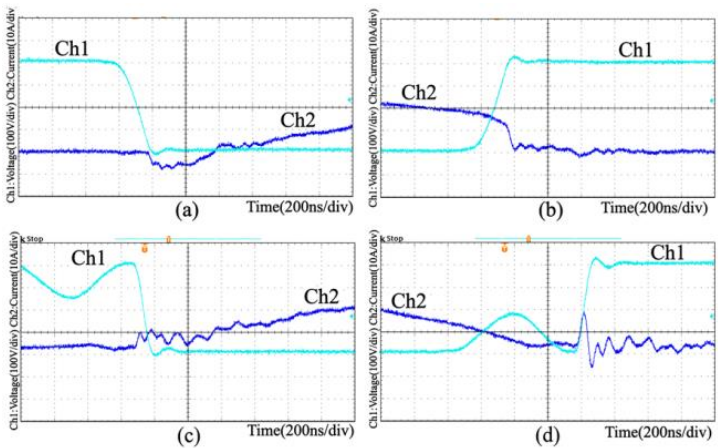

Fig. 12. (a) Turn-on and (b)Turn-off transitions of the switch. ZVS. (c) Turn-on and (d) Turn-off transitions of the switch. ZCS.

TABLE I. COMPONENT AND PARAMETER VALUES, SIMULATION AND EXPERIMENTAL

\begin{tabular}{|c|c|c|}
\hline Parameters & Symbol & Values \\
\hline Input Voltage & $V_{i n}$ & $400 \mathrm{~V}$ \\
\hline Output Voltage & $V_{o}$ & $300 \mathrm{~V}$ \\
\hline Output power & $P_{o}$ & $3 \mathrm{~kW}$ \\
\hline Switching frequency & $f_{s w}$ & $100 \mathrm{kHz}$ \\
\hline Resonant inductor & $L_{s}$ & $15 \mu \mathrm{H}$ \\
\hline Magnetizing inductance & $L_{m}$ & $217 \mu \mathrm{H}$ \\
\hline Resonant capacitors & $C_{S}$ & $130 \mathrm{nF} / 200 \mathrm{nF}$ \\
\hline Output capacitors & $C_{o}$ & $470 \mu \mathrm{F}$ \\
\hline Main switches & $S_{I-2}$ & IKW40H1203 \\
\hline Diodes & $D_{l-4}$ & APTDC20H1201G 8 \\
\hline Transformer & $T_{r}$ & SKYVFTR15 \\
\hline Input Voltage & $V_{i n}$ & $400 \mathrm{~V}$ \\
\hline Output Voltage & $V_{o}$ & $300 \mathrm{~V}$ \\
\hline
\end{tabular}

\section{B. Efficiency Comparison}

In this part, the efficiency of the DC-DC converter for auxiliary drives is discussed comparing two topologies of input 
half bridge converter (resonant and hard switching). In Figure 13, the comparison between HS (hard switching), ZVS, ZCS is shown while Figure 14 shows the efficiency comparison between converter switches operated at $0.5 \mu$ s dead time in ZCS operating region with switching frequency $112 \mathrm{kHz}$, resonant frequency $118 \mathrm{kHz}$ and $0.9 \mu \mathrm{s}$ delay used with $100 \mathrm{kHz}$ switching frequency. The efficiency of HS full bridge topology at maximum output power $3 \mathrm{~kW}$ is $92.1 \%$ and ZVS half bridge resonant converter is $92.6 \%$. There is an augmentation in $0.5 \%$ efficiency in comparison with HS. When the converter operates in the ZCS region at maximum output power $3 \mathrm{~kW}$, there is $94.3 \%$ efficiency achieved. The overall system efficiency is about $2 \%$ more than when using HS converter.

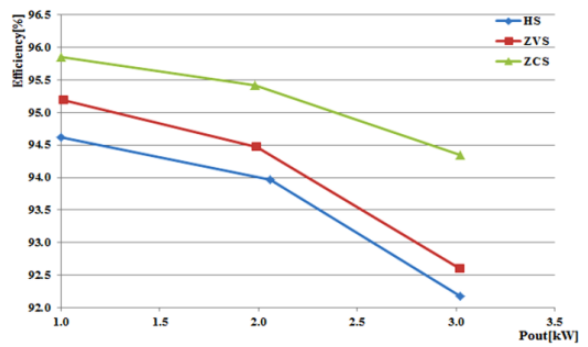

Fig. 13. Efficiency curves between HS and soft-switching.

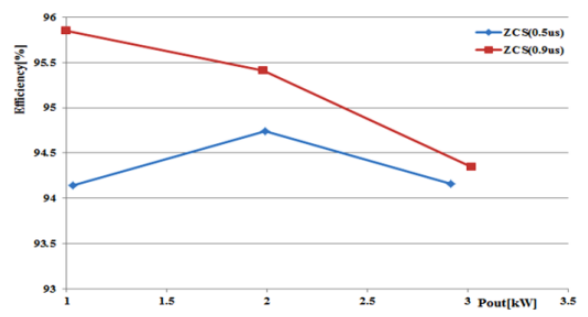

Fig. 14. Efficiency curves: ZCS operating region.

\section{CONCLUSION}

This paper presents an efficiency comparative study of HS and soft switching DC-DC converter for auxiliary power supply in traction with maximum efficiency of $94.3 \%$. The maximum output power of the resonant converter is $3 \mathrm{~kW}$ with $100 \mathrm{kHz}$ switching frequency. It has been simulated and laboratory tests investigated the ZVS and ZCS resonances separately in order to show the performance of the overall system efficiency. The output power levels can be increase up to $10 \mathrm{~kW}$ by changing transformer turns ratio. The efficiency obtained for hard switched DC-DC converter is $92.1 \%$ at maximum output power of $3 \mathrm{~kW}$. When the resonant frequency operates below the switching frequency, the converter has maximum efficiency $92.6 \%$ and the ZCS resonant converter has maximum efficiency of about $94.3 \%$. By varying the dead time interval between power switches in the ZCS operating region, the system efficiency was improved by $2 \%$ when compared to the conventional converter. The experiments were performed for steady state condition.

\section{ACKNOWLEDGEMENT}

This research has been supported by the Ministry of Education, Youth and Sports of the Czech Republic under the
RICE - New Technologies and Concepts for Smart Industrial Systems, project No. LO1607 and by project SGS-2018-009

\section{REFERENCES}

[1] X. Li, "A LLC type dual bridge resonant converter: Analysis, design, simulation and experimental results", IEEE Transactions on Power Electronics, Vol. 29, No. 8, pp. 4313-4321, 2014

[2] W. Chen, Z. Lu, "Investigation on topology for type-4 LLC resonant DC-DC converter", 39th Annual IEEE Power Electronics Specialist Conference, Rhodes, Greece, pp. 1421-1425, June 15-19, 2008

[3] H. Kato, H. Matsuo, T. Ito, S. Kawazu, D. Kawahara, S. Motomura, R. Hamaguchie, "Comparative analysis of full bridge and half bridge current resonant converter", IEEE 33rd International Telecommunications Energy Conference, Amsterdam, Netherlands, October 9-13, 2011

[4] Y. S. Dow, H. I. Son, H. D. Lee, "A study on half bridge LLC converter for battery charger on board", 8th International Conference on Power Electronics and ECCE Asia, Jeju, Korea, May 30-June 3, 2011

[5] B. Yong, F. C. Lee, A. J. Zhang, G. Huang, "LLC resonant converter for front end dc-dc conversion", APEC. Seventeenth Annual IEEE Applied Power Electronics Conference and Exposition, Dallas, USA, March 1014,2002

[6] P. Spanik, P. Drgona, M. Frivaldsky, A. Prikopova, "Design and Application of Full Digital Control System for LLC Multiresonant Converter", Elektronikair Elektrotechnika, Vol. 106, No. 10, pp. 75-78, 2010

[7] J. B. Lee, J. K. Kim, J. I. Baek, J. H. Kim, G. W. Moon, "Resonant Capacitor On/Off Control of Half-Bridge LLC Converter for HighEfficiency Server Power Supply", IEEE Transactions on Industrial Electronics, Vol. 63, No. 9, pp. 5410-5415, 2016

[8] V. V. S. K. Bhajana, P. Drabek, M. Jara, "Performance Evaluation of LLC Resonant Full Bridge DC-DC converter for auxiliary systems in traction", Revue Roumaine des Sciences Techniques - Serie Electrotechnique et Energetique, Vol. 60, No. 1, pp. 79-88, 2015

[9] J. I. Z. Chen, "A High Efficiency Full-bridge Converter", Journal of Electrical Systems, Vol. 8, No. 4, pp. 442-458, 2012

[10] J. W. Kim, J. K. Han, J. S. Lai, "APWM adapted half-bridge LLC converter with voltage doubler rectifier for improving light load efficiency", Electronics Letters, Vol. 53, No. 5, pp. 339-341, 2017

\section{AUTHORS PROFILE}

Veera Venkata Subrahmanya Kumar Bhajana received his B.E in Electronics and Communication Engineering from the Sapthagiri College of Engineering, Dharmapuri, Tamilnadu, India (University of Madras), in 2000, M.E from the P.S.N.A College of Engineering and Technology, Dindigul, Tamilnadu, India in 2005 and his $\mathrm{PhD}$ in Electrical Engineering from the Bharath University, Chennai, India in 2011. He has 11 years of teaching experience in various engineering institutes in India. He worked as a post-doc researcher at the University of West Bohemia, Czech Republic from August 2013 to June 2015. Since December 2011, he is working as Associate Professor in the School of Electronics Engineering at Kalinga Institute of Industrial Technology, India. He has presented papers in many reputed IEEE international conferences. His main areas of interest are Power Electronics Engineering, including soft switching DC to DC converters, AC-AC converters, and multilevel converters.

Pavel Drabek received his M.S. and Ph.D. degrees in Electrical Engineering from the University of West Bohemia (UWB), Czech Republic, in 2000 and 2004, respectively. From 2003 to 2005, he was a Design Engineer in Alltronic, Ltd., Pilsen. In 2005, he joined the UWB as an Assistant Professor at the Department of Electromechanics and Power Electronics. His main research interests include soft-switching inverters, AC-AC converters, multilevel converters, and electromagnetic compatibility (particularly lowfrequency interference) of power electronics converters. 